\title{
Ilian, Ilinca (2013): Julio Cortázar y Robert Musil: consonancias, divergencias y ecos. Madrid: Ediciones Clásicas; 237 pp.
}

Los dos últimos años han brindado múltiples ocasiones para volver a evocar la figura y obra de uno de los autores más destacados de la narrativa hispanoamericana del siglo pasado: en 2013 se celebró el quincuagésimo aniversario de la publicación de Rayuela y en 2014 el centenario del nacimiento de su autor y trigésimo aniversario de su muerte a la vez. Entre abundantes obras críticas que acompañaron el «boom» de las numerosas ediciones y reediciones de las obras cortazarianas en este período aparece también la presente monografía de Ilinca Ilian, profesora titular de la Universidad del Oeste de Timişoara, doctora en literatura comparada y ganadora de varios premios nacionales de traducción y crítica literaria. La joven investigadora ha dedicado hasta ahora especial interés a la prosa de Julio Cortázar, no solo en sus estudios críticos sino también con la traducción de su obra maestra Rayuela (Şotron), publicada en 2004.

El libro en cuestión se propone examinar los elementos literarios que revelan el espíritu creativo de Cortázar no tanto en la línea de las más osadas vanguardias artísticas -al florecimiento de las cuales el autor argentino en realidad se adelanta y que van mano a mano con los importantes movimientos de liberalización en la mentalidad de la sociedad occidental- sino más bien tomando en consideración los postulados del bigb modernism que esta novela no ha dejado atrás como podría pensarse, sino, todo lo contrario, los ha incorporado felizmente en su complejo engranaje narrativo, logrando de esta forma un paradigma de diálogo constructivo y siempre actual entre los principios modernistas por un lado y de todos los post-ismos por el otro, y sumando una pieza más al «efecto de totalidad» que produce su texto. Para ejemplificar este diálogo con el modelo del bigh modernism la autora halla el interlocutor de Cortázar en el autor austriaco Robert Musil y su obra El hombre sin atributos, cuyo protagonista $-\mathrm{y}$ en gran medida portavoz del autor-, Ulrich, ha pasado a formar parte, a su vez, de los héroes literarios de Cortázar. Según afirma y demuestra la investigadora, lo que más acerca a Cortázar a su maestro son «la carga vital de sus exploraciones» $\mathrm{O}$ «la seriedad con que se plantea una serie de preguntas éticas y gnoseológicas fundamentales». El compromiso de la autora se proyecta mucho más allá de una sencilla catalogación de influencias, alentándola a entablar de una manera sistemática y convincente no solo un diálogo entre dos novelistas sino también una animada discusión entre dos visionarios entusiastas. 
El estudio consta de seis apartados: una breve introducción, cuatro capítulos y conclusiones. El primer capítulo, «Un sorprendente caso de influencia literaria», presenta las circunstancias en las que Cortázar se familiarizó con la obra de Musil y el impacto inmediato y decisivo que esta produce en él. A continuación aborda el problema de la «recepción tergiversada de un escritor caracterizado por su apego a las ciencias por parte de un escritor que tiene una base filosófica irracionalista», corroborando esta consideración con los conceptos teóricos relativos a la producción y recepción de un texto literario (misreading, intentio auctoris, intentio operis, Zeitgeist etc.) para demostrar, a través de un minucioso análisis de trayectorias y preocupaciones filosóficas, estéticas y formales en muchos aspectos antagónicas de los dos autores, cómo la influencia de la obra musiliana en la de Cortázar se debe a una creative misreading y que las correlaciones establecidas derivan más del hecho de pertenecer ambos escritores a un ámbito intelectual común, marcado especialmente por la escuela de los existencialistas, que de una huella directa.

En el segundo capítulo, «Dos edades de la novela moderna», la autora determina en un repaso crítico de los estudios sobre las obras tratadas el concepto de novela en dos etapas del bigh modernism - la primera y la segunda mitad del siglo XX- a las que corresponden El bombre sin atributos y Rayuela, respectivamente. El análisis comparativo parte de las innovaciones (la estructura fragmentada, «los pasos continuos entre la historia y el ensayo», la «nueva relación con la temporalidad», el juego de distintas voces narrativas) aportadas por Musil, muchas veces considerado erróneamente como poco propenso a la modernidad (cuando a lo que se mostraba reacio era en realidad únicamente a los «experimentos pseudo innovadores»), y subraya el papel clave que desempeña el autor austriaco en el cambio de actitud respecto a la literatura debido a su «pasión por la invención realmente válida» que rechaza cualquier gesto creador condicionado por lo que Oliveira -en su vertiente de portavoz del autor- llamará «la Gran Costumbre» y «una certeza total». En Rayuela las consideraciones musilianas se vuelven más explícitas y -envueltas en una serie infinita de procedimientos experimentales y lúdicos- son llevadas a su culminación, abriendo un terreno de juego e interpretaciones personales inagotable. La autora concluye argumentadamente que los dos autores han conseguido con sus modalidades narrativas «desplazar la meditación sobre la crisis de la novela hacia lo que los dos consideran la verdadera causa de ésta: la confusión entre lo personal y lo impersonal en la edificación de los sistemas morales». 
Bajo el título «La conciencia infeliz» del tercer capítulo el análisis profundiza en los paralelismos, enfocándose en el parentesco entre los dos protagonistas de El bombre sin atributos y Rayuela, Ulrich y Oliveira, «intelectuales de segundo rango», solitarios e inadaptados a una realidad repetitiva y rutinaria cuyos signos más manifiestos son una búsqueda o, mejor, una espera pasiva pero permanente, por un lado, compensada por la dinámica actividad mental, por el otro, condición que los dos compartirían con la generación de los personajes «de la conciencia infeliz» hegeliana de la novela europea entre 1920 y 1940, pero que, señala la autora, «no representan sino la fase negativa de la investigación de los autores acerca de la subjetividad», «entre las esferas sentimental e intelectual», terminando por parodiar la doctrina con la defensa de un «segundo estado de conciencia» que favorece la inseparabilidad entre la razón y la irracionalidad: no importa que las confrontaciones de ideas en las que no dejan de sumergirse los dos hombres no acaben por resolverse, sino al contrario, son las indisolubles contradicciones y ambigüedades en las que desembocan como consecuencia del desdoblamiento sistemático de todo pensamiento. Apoyan la expresión de esta actitud invertida y ambivalente de los dos autores las convicciones transgresoras puestas en boca de Morelli -conforme la autora un «personaje intercesor, por el cual se exprime un arte poética de cierta forma utópica» de índole musiliana que manifiestamente cautivó a Cortázar- según las cuales lo que le incumbe al escritor no es aceptar la cultura occidental (la lógica aristotélica, la dialéctica judeo-cristiana, criterios de verdad y error) sino, todo lo contrario - en palabras de Ulrich- desafiar «la sistematización lógica», «la voluntad unidimensional» $\mathrm{y}$ «los impulsos terminantemente dirigidos de la ambición».

En el cuarto y último capítulo, con el sugerente título «Utopía y desencanto: amor y literatura» la autora prosigue y sintetiza magistralmente la línea metodológica de los capítulos anteriores explotando esta vez «las tentativas [de los escritores] de aunar la investigación ética con el quehacer literario», es decir, la capacidad de intervenir activamente, a través de la literatura, en el desarrollo del sistema de los valores sociales. Pone de relieve tres medios novelescos de los que se valen tanto Musil como su «seguidor» en su credo artístico con los que ambos consiguen con creces este fin, con o sin intención explícita. El primero es la autenticidad de los sentimientos, el segundo la inconfundible ironía, mordaz pero «carente de cinismo», ironía ambigua que en sintonía perfecta con el tercer medio - la superación del pensamiento binario-impide al lector la cristalización del sentido último. De esta manera, aunque el significado proporcionado por el texto no esté desprovisto de ideología, la lectura 
no significa un intento de adoctrinamiento del lector, sino al contrario, una provocación al diálogo que fomenta en él «fuerzas de creación». Así entendió Cortázar-lector el reto de El hombre sin atributos y así lo transmite al lectorcómplice de Rayuela.

La monografía que es objeto de nuestra revisión no es el primer estudio que fija su atención en la relación Cortázar-Musil, no obstante, la autora -revelando un exhaustivo y convincente dominio de los sobresalientes trabajos anteriores sobre el tema y partiendo ella misma de sus conclusiones- aporta a su vez elementos de máxima pertinencia que acaban no solo por iluminar matices significativos en el entendimiento de la vinculación entre los dos autores en cuestión, sino, en un sentido más amplio, constituyen una importante contribución a la teoría literaria contemporánea.

Cabe subrayar en este punto que el acercamiento propuesto no pretende para nada contestar los planteamientos posestructuralistas o posmodernos, que reconocen en Rayuela su «ambición antiliteraria», «la refutación radical del racionalismo», «las anticipaciones de la teoría de la opera aperta», «la intertextualidad», «la exploración profunda del lenguaje», lo lúdico y el papel del lector en la creación del texto literario. Su objetivo es únicamente poner en evidencia esta otra perspectiva dialógica que se ha quedado en segundo plano debido al efecto fulminante que han despertado en la crítica los procedimientos novedosos de la «novela total» cortazariana y así -obviando arriesgadas generalizaciones- «contribuir a una lectura más completa del autor argentino». Por otro lado, no se debe pasar por alto el hecho de que el análisis comparativo llevado a cabo en esta monografía arroja asimismo nueva luz sobre la obra de Musil y confirma con nuevos argumentos su merecido aunque tardío reconocimiento.

En definitiva, el estudio de Ilinca Ilian manifiesta una erudición admirable, un rigor científico y una potencia analítica que hacen juego con un estilo denso, pero claro y elegante, alejado de cualquier retoricismo. No podemos sino afirmar, con toda seguridad, que el resultado reúne méritos más que suficientes para convertirse en obra de obligada referencia en los estudios cortazarianos.

Maja Šabec

Universidad de Ljubljana 